\title{
From Utopia to Reality, a Path to Unveil: The Participation of Parents/Guardians in the Council of the Class
}

\author{
Paula Cristina Bento \\ EB 2/3, Oliveira do Hospital, Portugal
}

\author{
Teresa Sarmento \\ University of Minho, Braga, Portugal
}

\begin{abstract}
Nowadays, we intend school to be a border-less space, open to the educational community, where the roles of different educational actors can be complementary through the participation and opinion-sharing among all actors in the educational process. This research seeks to answer the following questions: 1. Is there a real participation of parents/guardians $(\mathrm{P} / \mathrm{G})$ in the council of the class $(\mathrm{CC})$ ? 2. At what level does it occur? and 3. How does it happen? This study, of a qualitative character, has been conducted on the basis of a case study. The analysis falls on the representations of the most important actors in this process - teachers, the director of the class (DC), and the representative of $\mathrm{P} / \mathrm{G}$ and students - as revealed in the interviews conducted with them. The diverse narratives of teachers and DC show the existence of a paradox at some moments, even though the statements converge on the need of a face-to-face and participative role in the CC. Some of them favor this position, recognizing that the contribution of these actors in the $\mathrm{CC}$ is a gain to everybody's work; Some are against it, sledging that their participation has not yet had repercussions on the group/class and considering that guardians are dispensable in the school body; Still, others manifest indifference to their presence in the CC. However, all of them recognize the existence of benefits and accept the participation of $\mathrm{P} / \mathrm{G}$, so that there can be an articulation of attitudes between the two perspectives, and consider important their action to the balance of the educational action. The students revealed a unanimous position in their opinions, invoking that $\mathrm{P} / \mathrm{G}$ ought to attend all meetings, so that they can get a perspective on the class, both on academic terms and on behaviors. The $\mathrm{P} / \mathrm{G}$ also identify themselves within the $\mathrm{CC}$, showing the certainty that their contribution will be beneficial to the teachers, because the latter will get to know the students better and recognize as well that, in this fashion, the $\mathrm{P} / \mathrm{G}$ get a more real perspective on how the class is evolving and the students benefit from the approved steps and from the articulation suggested with the $\mathrm{P} / \mathrm{G}$. Nonetheless, they did not lose the opportunity to mention that their presence in this school body is restricted to a few minutes. If their presence in this body continues to happen in such a way, the $\mathrm{P} / \mathrm{G}$ can be tempted to adopt an attitude of absenteeism in the $\mathrm{CC}$, and lead to their withdrawal towards the school.
\end{abstract}

Keywords: relationship, parental participation, council of the class (CC)

\section{Introduction}

The participation of parents/guardians $(\mathrm{P} / \mathrm{G})$ in Portuguese schools is two-fold: either in an individual level, to approach specific issues relative to a child/student, or in a collective level, when soughting an approach to the issues relative to children/students of a class. In this last case-that coincides with the focus of this

Paula Cristina Bento, Ph.D., professor, EB 2/3 de Oliveira do Hospital.

Teresa Sarmento, Ph.D., professor, Institute of Education, University of Minho. 
paper-this participation takes the fashion of a representation, with a parent/guardian assuming the representation of all $\mathrm{P} / \mathrm{G}$ of their children/students of the class. The action of this representative occurs at the level of the council of the class (CC), an organ composed of all the teachers of the class, the representative of the $\mathrm{P} / \mathrm{G}$, and the representative of the class (a student who represents all of his/her classmates). The opportunities for the $\mathrm{P} / \mathrm{G}$ to have an active voice and participate in the decision-making process of the $\mathrm{CC}$ are uphold in the legislation; however, our doubt about the effectiveness of this participation led us to realize the investigation that is on the basis of this article. So, this research seeks to answer the following questions: 1 . Is there a real participation of $\mathrm{P} / \mathrm{G}$ in the $\mathrm{CC}$ ? 2. At what level does it occur? and 3. How does it happen? The analysis falls on the representations of the most important actors in this process-teachers, the director of the class (DC), and the representative of $\mathrm{P} / \mathrm{G}$ and students - as revealed in the interviews conducted with them. The diverse narratives of teachers and DC, in syntheses, show the existence of a paradox at some moments, even though the statements converge on the need of a face-to-face and participative role in the CC.

\section{The Participation of $\mathrm{P} / \mathrm{G}$ in the $\mathrm{CC}$ as a Right and as an Utopia in the Fashion of a Possibility}

The participation in the school institution is not limited only to the fact that the $\mathrm{P} / \mathrm{G}$ are going to "communicate" something or "be present to"; that is, the participation presupposes the existence of a shared action among all participants in the educational action. It is a right inherent to the citizenship condition. All human beings, in Western societies, have the right to participate and express their whishes. Guerra (2002) highlighted that participation "is neither a present nor a favor" (p. 7), or in other words, "Participation is a value and a right of citizenship and its sine qua non condition" (Sanches, 2007, p. 93); it is a right of all citizens. Without participation, citizenship is not implemented, consequently, it is through the participating action that $\mathrm{P} / \mathrm{G}$ have the opportunity to practice citizenship and to make them directly listened to, when they themselves intervene or indirectly through their representatives.

Starting with the premise that the interaction of $\mathrm{P} / \mathrm{G}$ in the $\mathrm{CC}$ is established and interpreted by human beings, with all of the conditionalities inherent to their conditions as such, as stated by Silva and Stoer (2005), oftentimes transpose "to their actions, their (ir)rationalities, their interests, but also to their emotions and their feelings" (p. 7); that is, it is an interaction that requires consistency through the understanding between school and family, making them both avoid the "traps" and irrational interpretations, whence the presence of the $P / G$ in the CC may evidence itself as one of the ways of articulating the different educational perspectives of teachers and $\mathrm{P} / \mathrm{G}$.

In the scope of the organization of education, the $\mathrm{CC}$ arises as a space of thinking critically, a space of decision-making and participation, and a space of the different educational actors who intervene in the educational process. In this study, the presence of the $\mathrm{P} / \mathrm{G}$ in the $\mathrm{CC}$ is understood as a possibility of the participation of the family in the school; in this scope, the spaces school/family arise as two allies in the education of children and youths, being clear that, in the light of this goal, there exists a coordination and complement between the actions developed in each of the educational spaces. Besides being within the family that the first educational space is developed, family members still have the right and the duty to participate as key partners in the educational process of their children, without being allowed, under any circumstances, to distance themselves from the education of their children and youths (Sarmento, 2009). The dimension of their participation in the $\mathrm{CC}$ is inscribed in a collective foundation, so that the the representatives of the $\mathrm{P} / \mathrm{G}$ may 
have a say in the $\mathrm{CC}$, in the name of all $\mathrm{P} / \mathrm{G}$ and their children, to preserve the real interests of the students in the sense of their social integration and academic success.

\section{The DC in the Structure of Intermediate Management: Interface Among Different Educational Actors}

In an approach of interpretative analysis to the direction of the class, Sá (1995) recognized that it is integrated within the intermediate pedagogical structure of the schools, where the role of the DC, as liaison with the family, reveals one of its attributes, to which one can add the educational guidance of the students and the coordination of teachers. The DC is a figure with a just relevance, reflecting a "humanist image of the organization" (Sá, 1995, p. 4), her/his action being interpreted in the light of the well-being of the students, trying, whenever it is possible, to solve and to initiate mechanisms that meet their needs.

The action of the DC "is characterized by the task of facing and overcoming a variety of issues and challenges raised by the triangle that defines and delimits their social and institutional field of interaction" (Gomes, Antunes, Martins, \& Sarmento, 2012); in other words, the DC, as an interface in the relationship among several elements, has the task of guaranteeing support to the students, guiding them through their academic lives, being attentive to their behaviors, helping them in the fulfillment of their duties, keeping vigilant to all situations that might interfere with their success, supporting their integration in the class, and seeking to foster a climate of companionship among all the students. The DC is the person who establishes all required contacts with $\mathrm{P} / \mathrm{G}$, keeping them informed about the academic and behavioral evolution of their children. Relatively to teachers, the DC provides relevant information about the students regarding their behaviors and academic performance, organizes each student's file, collects all data about their academic lives and their socioeconomic surroundings, and seeks to know whether the students have any health problems that require special attention on the part of their teachers when they are enrolled in middle schools. These actions are performed by the means of interaction processes, where permanent dialogue and efficiency in communication are essential.

The DC may be a positive reference to the students, helping them develop positive behaviors and attitudes in schools and in the society. To the teachers of the $\mathrm{CC}$, they should make a positive contribution to allow their activities to be developed and to dignify the CC "as a truly pedagogical-educational structure" (Castro, 1995, p. 127). As far as $\mathrm{P} / \mathrm{G}$ are concerned, the $\mathrm{DC}$ can also function as a positive reference, conveying confidence and security, as a person whom the $\mathrm{P} / \mathrm{G}$ can trust and whom is always available to help them, being capable of more easily promoting $\mathrm{P} / \mathrm{G}^{\prime}$ involvement in the school life and their closest following up of their children's school trajectory. The author mentions the position of the role of the DC, in this context, calling him/her a "nuclear actor in fostering of the academic success of the students" (Castro, 1995, p. 127), which explains the relevance of his/her personal and professional profile.

Silva (2006) mentioned the issue of the distance between the culture of the school and the family, using these words:

To be true, nobody can state the "scientific" superiority of either culture over the other, but not all have the same "worth" in a given context, classifying them. Metaphorically, some of them have a great relevance, some others have a little relevance, and still some others have no relevance. (p. 283)

In all normative settings, the DC has a key role regarding the interaction between school-family-teachers 
and students, acting as liaison among them, and he/she ought not to assume a posture of superiority while performing his/her job with the $\mathrm{P} / \mathrm{G}$ who are often in a fragile situation, regarding the scholar organization, which inhibits them from making themselves heard and exposing the problems that afect their children. The DC, being an expert in cultural diversity, may give a little more attention to those who possess a culture more distant from the mainstream population of the school, in order to be able to achieve an understanding of what is happening in that family and with that child through a "family dialogue", to overcome the weaknesses, and to achieve academic success. Roldão (2007) considered that a good accomplishment in the coordination of the action of teachers, in the guidance of students, and in the mediation between the action of teachers and that of the other educational actors, depends on the achievement of a higher academic success and a greater degree of satisfaction among all educational actors.

The $\mathrm{P} / \mathrm{G}$, although they are represented in the $\mathrm{CC}$, have a limited scope of action when compared with the "cognoscenti" power of the teachers, term used by Formosinho (1980). According to Formosinho (1980), teachers "progressively controlled the processes of decision-making within the organization, both through the control of the necessary information needed to that process, and afterwards, through the access to office positions" (p. 309).

We would like to highlight that the relation between the school and the family, besides the advantages of articulation, responsibility, and joint cooperation among the diverse educational actors, about important aspects to the success of the students, is the relation developed in different dimensions of action. According to Silva and Stoer (2005), this relation might develop according to dimensions of action- "individual and collective" (pp. 16-17). The "individual" dimension corresponds to the private behaviors developed especially by the $\mathrm{P} / \mathrm{G}$, for the sake of the defense of his/her children's interests, both at school and at home; as regards the "collective" one, it applies to the protection of the general interests of all students.

Silva and Stoer (2005) highlighted the dimension of the "collective" performance, associating it with the "exercise of a role (instead of a voice)" (p. 17), because their presence in the DC is regulated by a law, that concedes their representation in the organ, a space where they fulfill the "role" of representatives and where it is not given enough time to them to make their "voice" heard about relevant issues to the success of the students. The presence of $\mathrm{P} / \mathrm{G}$ is marked by a flash presence in that organ, where they do not even "exercise a role"; that is, it is a practice adopted by most schools and accepted by $\mathrm{P} / \mathrm{G}$, although it is not consensual to all people, as it can be gathered from the testimony of an interviewed teacher, who desires to denounce this situation: "We have the presence of $\mathrm{P} / \mathrm{G}$ in the $\mathrm{CC}$ for a little time, say five minutes, they listen to some information, and then, go away". The short time that these actors spent in the CC can also be an inhibition factor to their participation. Estrela (2001) highlighted that "in the light of the changes that occurred in the concept and the role of the school, the role of teachers, formerly restricted to the classroom, have not ceased to broaden" (p. 121). Thus, according to Estrela (2001), a teacher is expected to perform several tasks, regardless of professional maturity of his/her talent or area of training, such as "moral educator, expert in human development and in human learning, technician of curricular development, expert in learning knowledge, evaluator, scholar guide, stimulator of school life, innovator, researcher, and agent of social change" (p. 121).

\section{Methodology}

In the investigation presented in this text, we are mainly interested in understanding how the participation of the $\mathrm{P} / \mathrm{G}$ in the $\mathrm{CC}$ occurs. Thus, in order to obtain the necessary information, some questions were addressed 
to the people intervening in the process, so as to get access to their representations regarding the participation of the $\mathrm{P} / \mathrm{G}$ in the $\mathrm{CC}$. To allow the possibility of a greater neutrality of the process, an interview guide was conceived, with some identical questions to be used in different interviews, to produce a triangulation of the data obtained from all of the actors. The reality that we have proposed ourselves to study includes teachers, $\mathrm{P} / \mathrm{G}$, and students, each of them having a partial perspective of the functioning and dynamics of the school; the vision of each group is also regulated by its respective life experience and culture.

The techniques used to gather their perspectives were the documental analysis, to characterize the school and the surrounding environment in the implementation of semi-structured interviews. The sample is composed of the director of the school district, all directors of the 5th and 6th grades, and two teachers per class (one of them with more years of teaching experience and the other one with less experience, they were not responsible for the direction of the class), aiming to verify the existence of different perspectives and experiences among these educational actors. The selected students were the delegates and sub-delegates of the class; and among the $\mathrm{P} / \mathrm{G}$, two $\mathrm{P} / \mathrm{G}$ of the $\mathrm{CC}$ were selected.

After a careful analysis of several interviews, different subcategories emerged. According to the dimensions and categories previously defined, a different color was attributed to each of them. Afterwards, all interviews were carefully read again, and each statement being marked with the color of its respective subcategory.

\section{Participation of the $P / G$ in the $C C$}

In the dimension of the participation of the representatives of the $\mathrm{P} / \mathrm{G}$, as we have been reflecting, Silva and Stoer (2005) verified that "Here, we find ourselves, again, faced with a situation that points undoubtedly to a dimension of collective action, of defense of the general interests (...)" (p. 18). In other words, the P/G' actions in the $\mathrm{CC}$ must be largely representative of all $\mathrm{P} / \mathrm{G}$ and they must be developed in the defense of the general interests of the group/class.

However, as Lima (2002) revealed:

Nowadays, a rigorous debate about the nature of citizenship and its exercise in the area of education must fall upon not so much on the need to give a voice to the parents, within the educational system, but rather on how to allow this voice to be expressed within this system. (p. 145)

That is to say, the presence of the $\mathrm{P} / \mathrm{G}$ in the $\mathrm{CC}$ characterizes itself as a way of allowing $\mathrm{P} / \mathrm{G}$ ' voice to be heard through their representatives within the education system, where the $\mathrm{CC}$ reveals to be the appropriate place for the $\mathrm{P} / \mathrm{G}$. In a joint action with the teachers, it is able to define congruent ways of acting, making it possible for the $\mathrm{P} / \mathrm{G}^{\prime}$ voice not to be suppressed, either because of inhibition on their part, or for lack of opportunity.

\section{Presence of the $\mathbf{P} / \mathrm{G}$ in the $\mathrm{CC}$}

From the analysis conducted in this subcategory, the answers from 12 interviewees (one teacher, one DC, and $10 \mathrm{P} / \mathrm{G}$ ) showing a character of unanimity.

According to P-9 ${ }^{1}$, we verified that the $\mathrm{P} / \mathrm{G}$ know the curriculum project of the class and they give their opinions regarding it, and they only manifest their opinion if some issues need reformulation, but on the other

\footnotetext{
${ }^{1}$ In order to put the identification in anonymous system, we transfer names of parents to $\mathrm{P}$ and a number. For directors of class and students, we proceeded as for parents (e.g., DC-1, S-8, and so on).
} 
side, P-9 also mentioned that the $\mathrm{P} / \mathrm{G}$ "accept everything that we suggested", as far as the curriculum project of the class is concerned, when their voice could also be "significant, from the educational and pedagogical point of view of (...)" (Lima, 2002, p. 143), which leads us to ask the following questions: 1 . In what way does the participation of the $\mathrm{P} / \mathrm{G}$ in the $\mathrm{CC}$ occurs? and 2. How do teachers conceive $\mathrm{P} / \mathrm{G}$ ' participation? In the light of the position of agreement and acceptance "cooperation" $\mathrm{P} / \mathrm{G}$ adopt in the $\mathrm{CC}$, can we say that, according to Parteman (1970; as cited in Diogo, 1998, p. 69), we are faced with a "pseudo participation"; that is to say, the lack of decision-making power with which these actors are confronted for their action to be taken into consideration in this organ leads them to develop an attitude of agreement with everything they are presented with. The presence of the $\mathrm{P} / \mathrm{G}$ in this organ being an alternative to the presence of a collective of $\mathrm{P} / \mathrm{G}$, their direct participation would constitute "a ditch between the decisions and the decision makers", as mentioned by Diogo (1998).

There is no meeting to prepare and analyze the issues addressed in the CC. According to P-6's opinion, there is no relationship among the $\mathrm{P} / \mathrm{G}$, most often, they do not even know each other, which can explain the absence of feedback between the representative of $\mathrm{P} / \mathrm{G}$ and other $\mathrm{P} / \mathrm{G}$.

For $\mathrm{P}-13$, the presence of $\mathrm{P} / \mathrm{G}$ in the $\mathrm{CC}$ represents the fulfillment of a legal duty, rather than a real participation or involvement.

Thus, as one can verify:

I think their involvement would be greater, if, after the meeting, a parent/guardian contacted with the other $\mathrm{P} / \mathrm{G}$ and let them know the issues that were addressed in the $\mathrm{CC}$, and vice versa (...). CC is more the fulfillment of a legal duty than the participation or involvement. (P-13, with 18 years of service)

Thus, it seems that $\mathrm{P} / \mathrm{G}$ also assume their presence in the $\mathrm{CC}$ as a fulfillment of the law, they are present in it because they have the duty to attend meetings and keeping what is decided by the law, but they do not participate. One could say that there was a participation or involvement on the part of $\mathrm{P} / \mathrm{G}$ if there was an exchange of information between the DC and the P/G about what happened in the meetings. Afterwards, if they would jointly conduct to reflect on measures and ways of acting that supported their children and made teachers' tasks easier, consequently, it will contribute to a greater academic success of students.

From the analysis and the reflection upon the representations provided, 10 answers fall under this category: five from the DC, one from the teacher, and four from the $\mathrm{P} / \mathrm{G}$. They showed coherence when they mentioned that the presence of the $\mathrm{P} / \mathrm{G}$ in the $\mathrm{CC}$ as not been relevant in that organ, as it can be read in the selected testimonies:

It does not mean much, for example, in my case, the representatives have always attended, one of them is even a teacher of basic education, and even she does not provide any contribution. (DC-1, with 20 years of service)

One notices, in DC-1's testimonies, that the presence of $\mathrm{P} / \mathrm{G}$ in the $\mathrm{CC}$ reflects the fulfillment of a legal duty and the right that is given to $\mathrm{P} / \mathrm{G}$ to attend the $\mathrm{CC}$, but in reality, their acting has not provided any contribution to that organ, i.e., the effects of what they do are neither visible nor felt. (DC-3)

On the other side, DC-7 presented other indicators that may make it more difficult to the participation of the $\mathrm{P} / \mathrm{G}$ in the $\mathrm{CC}$ :

Because $\mathrm{P} / \mathrm{G}$ also do not have expectations regarding school, I think they have not given any contribution related to the students, regarding the participation of $\mathrm{P} / \mathrm{G}$ in the CC. (DC-7, with 23 years of service)

As DC-8 put it, "Their presence is meaningless", which is corroborated by T-15 when he stated, "but I do not see them participating, they are indifferent". Using again the typology developed by Lima (2003), one 
could fit into the criterion of involvement of the $\mathrm{P} / \mathrm{G}^{\prime}$ attitude in the $\mathrm{CC}$, which reveals a passive participation, showing indifference and lack of information, and therefore, avoiding to intervene. In the eyes of the organization, this strategy of participation is considered as non-involvement, because the $\mathrm{P} / \mathrm{G}$, as a minority represented in the $\mathrm{CC}$, may not want to assume consequences from their participation, declining their right to make decisions and proposals in favor of the teachers; however, this does not mean that their attitudes may not have some impact on the class.

\section{Which Areas P/G May Intervene}

This space allow us to verify in which "areas $\mathrm{P} / \mathrm{G}$ may have a more significant intervention", so an attitude of coordination and cooperation can be developed between the school and the family, where their action can reflect commitment and cooperation within the academic institution.

After defining the subcategories in this area, we have proceeded to their analysis, interpretation, and discussion.

One verified that, by crossing information, in the 11 answers gathered from six teachers, three DC, and two $\mathrm{P} / \mathrm{G}$, there exists no congruence among the selected testimonies, regarding the participation of the $\mathrm{P} / \mathrm{G}$ in the actions developed by the school.

As we can verify:

There was a Christmas party open to the community, $\mathrm{P} / \mathrm{G}$ attended and watched their little children making presentations, in the end, they degusted the food they took with them (...). P/G enjoyed it, they fraternized with other people and got to know some teachers they did not yet know, teachers fraternized with all the students and their families. (DC-5, with 26 years of service)

According to DC-5, the $\mathrm{P} / \mathrm{G}$ adhered with satisfaction to the Christmas party promoted by the school, so there could be a moment of fraternization between the scholar community and the family. This gathering allowed the $\mathrm{P} / \mathrm{G}$ and the teachers to get to know each other, as intervening actors in the educational process.

$\mathrm{T}-13$ and T-16 showed different opinions regarding the participation of the $\mathrm{P} / \mathrm{G}$ in the actions developed by the school, mentioning that the $\mathrm{P} / \mathrm{G}$ do not attend meetings even though the themes are of recognized interest and importance to the children, which evidences the detachment and disinterest on the part of the $P / G$ for the actions that the school develops to foster the academic success of the young people.

$\mathrm{T}-14$, when referring to the supervision in the study, declared that the $\mathrm{P} / \mathrm{G}$ need to talk more with their children at home about what has happened in school, which leads us to the theory defended by Silva (2003), who mentioned that $\mathrm{P} / \mathrm{G}$ ' interpretation and the academic interpretation of their relationship is different. Besides this course of action not being available to teachers, other factors may be impeditive to the $\mathrm{P} / \mathrm{G}$ ' actions being "well seen" and obtain the success desired by the school, as DC-4 mentioned in the case of her class, even those $\mathrm{P} / \mathrm{G}$ who want to help neither have the professional nor academic possibilities to do so.

The supervision in study, the realization of homework, and the consolidation of acquired knowledge are the great concerns shown by this actor. The words of the S-8 conveyed a duty that the P/G should have in this scope, rising as a condition for the students to get good grades.

\section{Conclusions}

The theme of the investigation that is presented here highlights the presence and participation of the $\mathrm{P} / \mathrm{G}$ in the $\mathrm{CC}$ as a joint action of sharing and collaboration among all actors involved in the education of children and 
youngsters, in order to make the articulation and agreement between the $\mathrm{P} / \mathrm{G}$ and the school in the educational process of their children possible and to promote the success of each student and the group/class.

This investigation also addressed the educational action, where families, as the most important and main intervenient party in this process, cannot be dissociated from the school/CC, because it is within this setting and with these actors, that their actions get more strength. Within this large field of study, we focused our attention on the interpretative analysis of the representations of the different actors involved in the educational process, seeking answers to the following questions: 1 . Is there an effective participation of the $\mathrm{P} / \mathrm{G}$ in the $\mathrm{CC}$ ? 2 . At what level does this participation occurs? and 3. What is teachers' conception about participation?

In this sense, the study tried to deepen the participation and the involvement of the $\mathrm{P} / \mathrm{G}$ in the $\mathrm{CC}$ theoretically and empirically. Through diverse legislations - Constitution of the Republic, Basic Law of the Education System, Decree-Laws, among other legislations, and through the speeches made about the participation of $\mathrm{P} / \mathrm{G}$ in the school, we show that the presence and action of these actors in the scholar institution is deemed important. With more recent measures, the political power reinforces the importance attributed to that participation, which is evident in Decree-Law No.137/2012 (article 44, paragraph (c), (ii)), in which representatively continues to be attributed to two elements of the $\mathrm{P} / \mathrm{G}$ in the $\mathrm{CC}$, as a form of democratization, participation, and humanization of the school. On the other hand, the participation in the school is conceded in a dissimulated fashion, since in the same day, through the same Decree-Law, and with the revocation of the 32nd article, subheading one of paragraph (c) removed P/G from the pedagogical council, even though the districts, in special cases, may keep that presence if the educational projects and the internal statute allow it.

The teachers and the DC also showed in their narratives that they are not very distant from the political power; the verbalizations denote the existence of a paradox regarding the presence and participation of the $\mathrm{P} / \mathrm{G}$ in the CC. At some moments, the discourses converge to the presence need of these actors in the $\mathrm{CC}$, as a way of collaboration and articulation of attitudes between the family and the school, and recognize that their participatory actions are fundamental to the success of the students, admitting their benefits. At other moments, the teachers revealed some discomfort with their presence in this organ, as T-4 mentioned, "The experience of the $\mathrm{P} / \mathrm{G}$ in the interpolate meetings is something to be forgotten", considering that it is not relevant and it has not yet carried any contribution to the group/class, so the teachers consider it unnecessary. We notice that there is some anxiety in the teachers and the DC about being able to immediately see and obtain the results of the actions developed by the $\mathrm{P} / \mathrm{G}$, forgetting that, in education, the effect of their intervention may not be noticed in a direct way on the students, some time is required until these results crystalize and become visible in the long run, because, as a child grows, she/he internalizes the advice and observations that are given to her/him, takes conscience of her/his responsibilities and attitudes, builds attitudes based on previous learning, and starts to show the team work developed by her/his teachers and P/G. Other teachers are indifferent to the presence of the $\mathrm{P} / \mathrm{G}$ in this organ, however, they revealed unanimity in considering that the actions developed by the $\mathrm{P} / \mathrm{G}$ is important to the students, bringing them benefits. The teacher who assumes this attitude regard participation as a way of longitudinal articulation between the perspectives of the school and those of the families, basing their position in the need of a balance in the educational action, which leads us to state that, globally, the position of the $\mathrm{P} / \mathrm{G}$, in the eyes of the teachers of the $\mathrm{CC}$ in this school, is not recognized with the importance that is attributed to it by the law. The conception of participation exhibited by teachers is limited only to the presence of the $\mathrm{P} / \mathrm{G}$ in the $\mathrm{CC}$, even if it is a silent one, revealing a shallow conception of this action. In this scope, the passivity of the $\mathrm{P} / \mathrm{G}$ may be understood in the light of the theoretical perspective of 
the typology of Lima (2003), being embodied in the organizational plan of action, and it reveals an attitude of detachment, alienation, and disinterest of these actors; towards the scholar institution, they adopt a posture of absence of an active participation. It takes the shape, thus, of a "non-involvement" or of an "involvement without expression"; the $\mathrm{P} / \mathrm{G}$ are not exempt of responsibilities, because their presence makes them committed; however, they leave to the teachers and the DC the role of decision makers, yet, they neither expose themselves directly, nor assume the actions developed in the $\mathrm{CC}$.

The $\mathrm{P} / \mathrm{G}$, in general, also agree with their presence in the $\mathrm{CC}$, they are convinced that their contribution shall be beneficial for the teachers, who become to know their children better; they also get a general perspective of the functioning of the class. Notwithstanding, they mentioned the short time they are allowed to be present in this organ, about 10 minutes, which causes them much "frustration". For all that, we were able to know and present in this study, we can state that the presence of the $\mathrm{P} / \mathrm{G}$ in the $\mathrm{CC}$ is humiliating to some of them, they feel that they are just present in body, and 10 minutes after the beginning of the meeting, they are invited to leave. In these terms, their presence in the CC may lead to the absenteeism of the $\mathrm{P} / \mathrm{G}$ in this organ and their withdrawal towards the school. We do not recognize that there can be a joint participation and thinking between the teachers and the $\mathrm{P} / \mathrm{G}$, because of the restriction of presence that is imposed by the school on these elements, which allow them to remain in the $\mathrm{CC}$ only during the information briefing. However, we also verify that, during the short time the $\mathrm{P} / \mathrm{G}$ present in the $\mathrm{CC}$, their concerns converge to address issues related to their children and their actions are not directed to the collective dimension of the group/class. On the other hand, we verify that there is a detachment of the $P / G$ towards school, in such a way that the $P / G$ mentioned that they are not contacted by the representative of the $\mathrm{P} / \mathrm{G}$ and that they do not even know her/him.

Some areas where the $\mathrm{P} / \mathrm{G}$ can have a greater action have been identified, so there is an attitudinal coordination between the school and the family, and the actions of some are not devalued by the others, but are complementary and foster the success of all students. In this path, the $\mathrm{P} / \mathrm{G}$ have identified as beneficial to the development of the actions of the $\mathrm{P} / \mathrm{G}$, being defined with their collaboration, according to the needs that they themselves feel and that the school shows, with this measure being in accordance with the success of the action and of the presence of a larger number of $\mathrm{P} / \mathrm{G}$.

One verifies that it is through the DC as intermediate manager that all of the pedagogical, administrative, and social processes of the class are developed; the DC's function is of recognized importance in this management organ of intermediate management, leading him/her to have a function of interface between the school and the $\mathrm{P} / \mathrm{G}$ and making this actor the main stimulator in the proximity or distancing between the $\mathrm{P} / \mathrm{G}$ and the school. However, we believe that, in this school, the relationships being created, of proximity between the $\mathrm{DC}$ and the $\mathrm{P} / \mathrm{G}$, as far as it was possible for us to verify, through the study that we realized, may conquer a complicity among these elements, making it possible to change the posture of the $\mathrm{P} / \mathrm{G}$ towards the school and the $\mathrm{P} / \mathrm{G}$. The existence and quality of these interactions may become reflected in a more dynamic action with their representatives, so these, in the $\mathrm{CC}$, do not become unprotected of representative content of all the $\mathrm{P} / \mathrm{G}$ and can intervene in a collective dimension, where everybody's worries may converge in the interests of all.

From the above analyses and discussions, we can unveil that the participation of the $\mathrm{P} / \mathrm{G}$ in the $\mathrm{CC}$, in this scholar reality, stands on an utopian action of these actors. It is limited to an act of presence, without any further meaning, where the ritual of the presence fulfills the intention expressed in the law, without having a really effective action from their participation. 


\section{References}

Castro, E. (1995). O diretor de turma nas escolas portuguesas, o desafio de uma multiplicidade de papéis (The director of the class in Portuguese schools, the challenge of a multiplicity of roles). Porto: Porto Editora.

Diogo, J. (1998). Parceria escola -Família, a caminho de uma educação participada (School—Family partnership, a way to a participated education). Porto: Porto Editora.

Estrela, T. (2001). Questões de profissionalidade e profissionalismo docente (Issues of professionality and professional decency). In T. Manuela (Org.), Ser professor no limiar do século XXI (Being a teacher in the frontier of the 21st century) (pp. 113-142). Porto: ISET.

Fontoura, M. (2006). Do projeto educativo de escola, aos projetos curriculares, fundamentos, processos e procedimentos (From the educational project of the school to the curricular projects, foundations, processes and procedures). Porto: Porto Editora.

Formosinho, J. (1980). As bases do poder do professo (The foundations of the power of the teacher). Portuguese Journal of Pedagogy, 14, 301-327.

Gomes, C., Antunes, F., Martins, F., \& Sarmento, T. (2012, July). A direção de turma entre racionalização, fragmentação e diversidade de culturas: Testemunhos e interpretação (The direction of the class between rationalization, fragmentation and culture diversity: Testimonies and interpretation). Paper presented at The IV Conference of Sociology of Education. The Education in the Global and Information Society (pp. 1-12), Oviedo, Spain.

Guerra, M. (2002). Os desafios da participação: Desenvolver a democracia na escola (The challenges of participation: Developing democracy in the school). Porto: Porto Editora.

Guerra, M. (2003). Tornar visível o quotidiano: Teoria e prática de avaliação qualitativa das escolas (Making daily life visible: Theory and practice of the qualitative evaluation of schools). Porto: ASA Editores.

Lima, J. (2002). A presença dos pais na escola: Aprofundamento democrático ou perversão pedagógica (The presence of parents in the school: Democratic improvement or pedagogical pervension?). In J. Lima (Org.), Pais e professore-Um desafio à cooperação (Parents and teachers-A challenge to collaboration) (pp. 133-173). Porto: ASA Editores.

Lima, L. (2003). A escola como organização educativa: Uma abordagem sociológica (The school as educational organization: A sociological approach) (2nd ed.). São Paulo: Cortez.

Marques, R. (1997). Ligar a escola ao meio: Criar redes de apoio aos alunos (Connecting school to its surrounding environment: Creating support networks for students). In D. Davies, R. Marques, \& P. Silva (Eds.), Os professores e as famílias: A colaboração possivel (Teachers and families: The possible collaboration) (pp. 55-60). Lisbon: Livros Horizonte.

Roldão, M. (2007). O diretor de turma e a gestão curricular (The director of the class and curricular management). Lisbon: Books of Educational Organization and Management.

Sá, V. (1995). Para além dos discursos: A face oculta do diretor de turma (Beyond speeches: The hidden face of the director of the class). Paper presented at The 3rd Conference of the Portuguese Society of Sciences of Education, Lisbon, University of Lisbon (FPCE).

Sanches, F. (2007). Construindo a cidadania democrática: Valores emergentes do discurso político no período revolucionário (1974-1975) (Building democratic citizenship: Emerging values of the political speech in the revvolutionary period (1974-1975)). In M. F. Sanches, F. Veiga, F. Sousa, \& J. Pintassilgo (Orgs.), Cidadania e liderança escolar (Citizenship and school leadership) (pp. 71-107). Porto: Porto Editora.

Sarmento, T. (2009). Children and citizenship: Participative approaches in educational projects. In T. Sarmento (Org.), Infancy, family and community: Children as social actors (pp. 43-68). Porto: Porto Editora.

Silva, P. (2003). Escola-família, uma relação armadilhada, interculturalidade e relações de poder (School-family, a trapped relationship, interculturality and power relationships). Porto: Edições Afrontamento.

Silva, P., \& Stoer, S. (2005). Do pai colaborador ao pai parceiro: A reconfiguração de uma relação (From the collaborative father to the partner father: The reconfiguration of a relationship). In P. Silva, \& S. Stephen (Orgs.), Escola-família, uma relação em processo de reconfiguração (School-family, a relationship in a process of reconfiguration) (pp. 13-28). Porto: Porto Editora.

Tuckman, B. (1994). Manual de investigação em educação: Como conceber e realizar o processo de investigação em educação (Manual of invesatigation in education: How to design and implement the process of investigation in education) (4th ed.). Lisbon: Calouste Gulbenkian Center. 